\title{
Acute Gastric Dilatation Resulting in Gastric Emphysema Following Postpartum Hemorrhage
}

\author{
Suhail Aslam Khan, ${ }^{1}$ Edmond Boko, ${ }^{1}$ Haseeb Anwar Khookhar, ${ }^{1}$ Sheila Woods, ${ }^{2}$ \\ and A. H. Nasr ${ }^{1}$ \\ ${ }^{1}$ Department of Surgery, Our Lady of Lourdes Hospital, Drogheda, County Louth, Ireland \\ ${ }^{2}$ Department of Radiology, Our Lady of Lourdes Hospital, Drogheda, County Louth, Ireland \\ Correspondence should be addressed to Suhail Aslam Khan, tahirkheli73@gmail.com
}

Received 11 February 2012; Accepted 12 April 2012

Academic Editors: C. Foroulis, M. Nikfarjam, and M. Rangarajan

Copyright ( 2012 Suhail Aslam Khan et al. This is an open access article distributed under the Creative Commons Attribution License, which permits unrestricted use, distribution, and reproduction in any medium, provided the original work is properly cited.

Acute gastric dilatation is a rare entity, with varying aetiologies the majority of which are benign. Delay in diagnosis and treatment could result in sequelae such as gastric emphysema (pneumatosis), emphysematous gastritis, gangrene, and perforation. Gastric emphysema as a result of a benign nongangrenous condition such as gastroparesis, adynamic ileus can be successfully managed conservatively. Here, we present an interesting case of acute gastric dilatation resulting in gastric emphysema following massive postpartum hemorrhage.

\section{Introduction}

Acute gastric dilatation is a rare entity, with varying aetiologies, the majority of which are benign. Prompt recognition and appropriate management are essential to prevent sequelae such as gastric emphysema (pneumatosis), emphysematous gastritis, gangrene, and perforation [1-4]. Like other sequelae of acute gastric dilatation, the development of gastric emphysema may also reflect other intra-abdominal pathology, and its presence can suggest gangrenous changes of the stomach or colon and, therefore, represents a surgical emergency [1-3]. However, gastric emphysema can also occur as a result of a benign, nongangrenous condition, such as gastroparesis and adynamic illeus and can be successfully managed conservatively [5-7]. Here we are presenting an interesting case of acute gastric dilatation resulting in gastric emphysema following acute management of postpartum hemorrhage.

\section{Case Report}

A 40-year-old African gravid 3/para 3 woman was admitted to the intensive care unit (ICU) following a caesarian section for placental abruption and fetal distress. She was booked for antenatal care at approximately 34 weeks of pregnancy with antenatal care prior to that done in Africa for this pregnancy. Her initial assessment was satisfactory (Tables 1 and 2), but in the background history, it was noted that she was suffering from constipation and gestational diabetes mellitus in her last pregnancy (Table 2 ) and was poorly compliant with insulin therapy.

She underwent emergency C-section after she presented with antepartum haemorrhage, and intraoperative findings were a low-lying placenta with large retroplacental clot with abruption. Postoperatively, she continued to bleed per vagina in ICU and received 7 units of red cell concentrate (RCC), 4 units of plasma, 4 pools of platelets, and an oxytocin infusion. Despite treatment, she continued to bleed and was transferred back to theatre, where a uterine tamponade balloon was successfully inserted. Her total blood loss was estimated in excess of 3 litres.

On the same evening, she began to complain of abdominal pain. On examination, her vital signs were within the normal range. Abdominal examination revealed a distended abdomen with tenderness in the epigastrium and left upper quadrant and was tympanic to percussion over the 
TABLE 1: Antenatal history.

\begin{tabular}{ll}
\hline Date of booking & $22 / 03 / 2011$ \\
LMP, EDD, gestation & $28 / 7 / 10,4 / 5 / 11,33$ wks, and 6 days \\
Cycle length & 28, regular \\
Maternal risk category & Low risk \\
Allergies & Flagyl, Chloroquine \\
Drugs in pregnancy & Antimalarial tabs and folic acid \\
Booking BP, pulse & $126 / 76,74 /$ min \\
Smoking, alcohol & None \\
& H/O essential HTN on med for 6 \\
Medical conditions & months in 2010, Rec UTIs, \\
& gestational diabetes in previous two \\
Family history & Sickle cell anemia, DM type 1 \\
Surgical history & Appendicectomy \\
\hline & Ultrasound \\
\hline EDD by LMP & $4 / 5 / 11$ \\
EDD by USS & $4 / 5 / 11$ \\
BPD & 87.8 mm \\
ABD circumf. & 331.3 \\
Placental site & Upper ant \\
Wt differential & 454 gms \\
Growth centile & $>90$ \\
Presentation & Cephalic \\
Fetal cardiac activity & Present \\
Head circumf. & 306.7 \\
Femur length & 77 mm \\
Fetal wt & 3113 gms \\
CTG & Satisfactory \\
\hline & \\
&
\end{tabular}

TABLE 2: Record of previous pregnancies.

\begin{tabular}{ll}
\hline Year & 2001, Nigeria \\
\hline Gestation & 39 wks \\
Antenatal problems & No record \\
Mode of delivery & Spontaneous, vertex, hospital \\
Perineal problems & Infected episiotomy \\
Outcome & Live birth, 3690 gms male \\
\hline Year & 2003, Ireland \\
\hline Gestation & 40 wks \\
Antenatal problems & Gestational diabetes \\
Onset & Spontaneous \\
Mode of delivery & Spontaneous, vertex, hospital \\
Outcome & Live birth, 3890 gms female \\
\hline Year & 2006, Ireland \\
\hline Gestation & 40 wks \\
Antenatal problems & Gestational diabetes, insulin given \\
Onset & Induced \\
Mode of delivery & Spontaneous, vertex, hospital \\
Outcome & Live birth, 3790 gms male \\
Neonatal problems & Yes; SCBU for BSL monitoring for 3 days \\
\hline
\end{tabular}

epigastric region. There was no guarding or rigidity noted. An abdominal X-ray showed significant gastric distension with diffusely noted gas pattern consistent with gastric emphysema (Figure 1). CT confirmed air in the stomach wall, with moderate abdominal and pelvic fluid, which was attributed to her earlier C-section (Figure 1). An urgent upper GI endoscopy was arranged which revealed a normal oesophagus, food in the stomach, and, on washing, revealed an oedematous beefy red, friable mucous-coated stomach mucosa extending over greater curvature from midstomach towards the fundus (Figure 2). Following consultation with the upper GI unit in a tertiary referral centre, this patient was managed conservatively with gastric drainage via nasogastric tube, broad-spectrum antibiotic cover, oral sucralfate, and total parenteral nutrition with close monitoring in ICU.

Her further clinical course was uneventful, and she responded very well to conservative management. A repeat CT, one week later, showed absence of gastric wall gas or free air (Figure 3). The large and small bowel loops appeared normal, and she was discharged home.

\section{Discussion}

Acute gastric dilation was first described by Powell et al. in 2003 [1], and it can be as a result of eating disorders, hemorrhage/trauma resuscitation, volvulus, medications, electrolyte abnormalities, infections, superior mesenteric artery syndrome, diabetes mellitus and slow gut transits causing chronic constipation [1-11]. It can have devastating consequences and has a reported mortality rate of $80 \%$ to $100 \%$ as a consequence of gastric necrosis and perforation [1-4].

Acute gastric dilatation can result in gastric emphysema, emphysematous gastritis, and ischemic necrosis. Ischemic necrosis, in the case of gastric dilatation, is postulated to be due to venous insufficiency $[1,5,6]$. Pressure in the stomach lumen must be $>14 \mathrm{~mm} \mathrm{Hg}$ to exceed gastric venous pressure and lead to ischemia $[1,3,4]$. Gastric emphysema is also a rare finding with only a few cases reported in the literature. Gastric emphysema resulting from a violation of mucosal integrity followed by forceful entry of air between the gastric layers is called noninfectious gastric emphysema $[5,6]$. The other extremely rare condition that was first described by Fraenkel in 1889 as emphysematous gastritis is due to infection [9-11]. The most commonly involved microorganisms are streptococci, Escherichia coli, Pseudomonas aeruginosa, Clostridium perfringens, and Staphylococcus aureus [10].

Gastric emphysema secondary to mechanical aetiologies is far more common than primary gastric emphysema. Causes include obstruction, trauma, and rupture of pulmonary bullae, enteric tube placement, and upper endoscopic procedures [1-8]. In these cases, the intraluminal gas dissects into the gastric wall through a mucosal tear or defect. The tear usually results from increased intraluminal pressure secondary to an obstruction or as a direct result of trauma. The reported mortality in this group, although lower than the mortality associated with gastric emphysema, is still high at $6 \%$ to $41 \%$ [3-5]. While other authors 


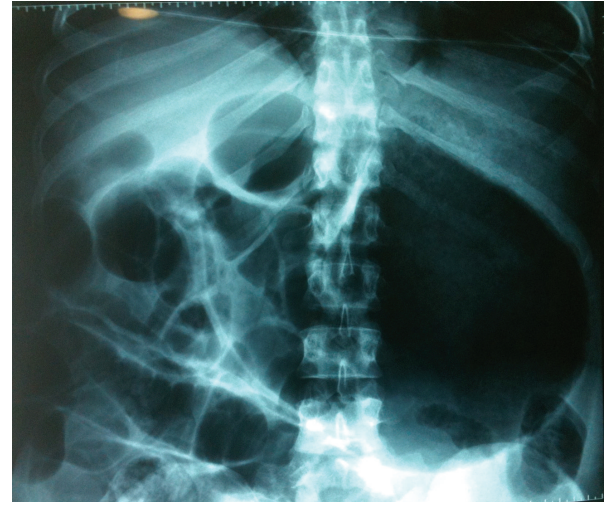

(a)

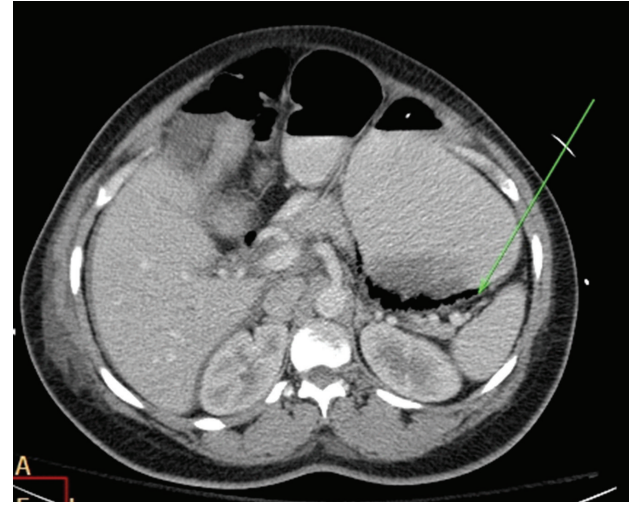

(b)

Figure 1: Plain film of abdomen and CT abdomen showing gastric dilatation of stomach and emphysema (arrow).

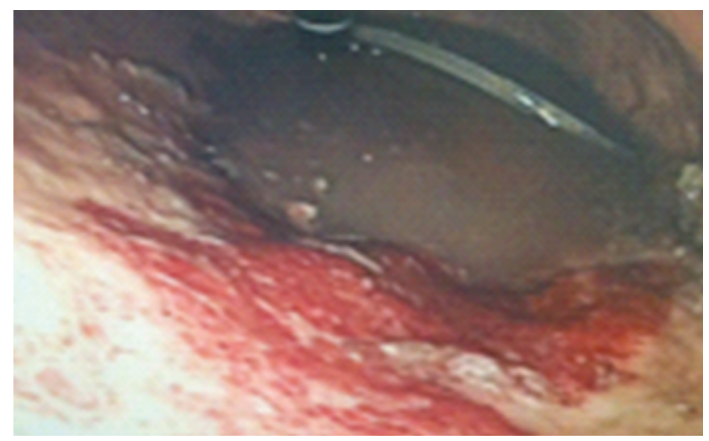

FIGURE 2: Upper GI endoscopy: showing oedamatous beefy red mucosa along the greater curvature of stomach.

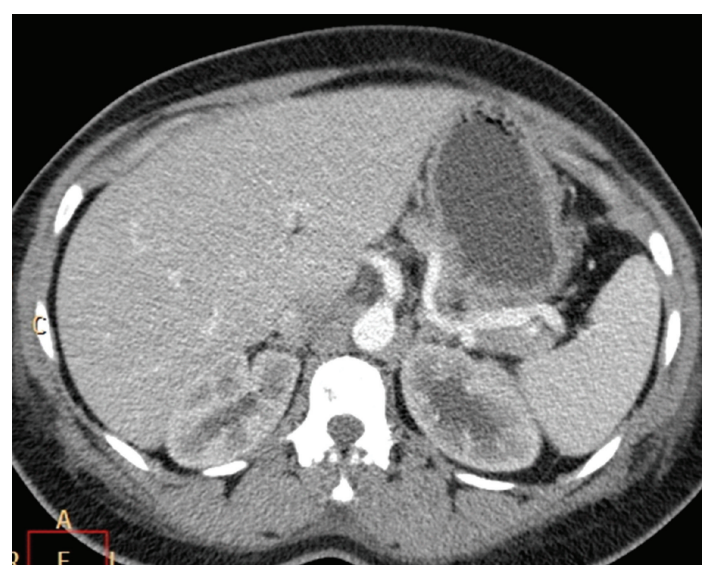

FIGURE 3: Follow-up CT abdomen after a week shows resolution of gastric emphysema.

describe gastric emphysema secondary to bowel or gastric outlet obstruction, Cho et al. highlighted the association of gastric emphysema causing adynamic ileus with postpartum hemorrhage, but gastric emphysema specifically associated with caesarian section and intrapartum hemorrhage has not been reported [7].
Clinically, patients with infectious gastric emphysema appear septic and complain of fever, chills, and abdominal pain [2, 9-11]. These signs and symptoms could be the main differentiating features separating infectious gastritis from symptoms of acute gastric dilation resulting in gastric emphysema, which can be initially vague with progressive abdominal distention and accompanying pain [9-11]. Plain abdominal radiographs or abdominal computed tomography are diagnostic. In the majority of cases, emphysema occurs along the greater curvature of the stomach. The lesser curvature and pyloric regions of the stomach tend to be spared $[2,5,12,13]$. In a pictorial essay, Johnson et al. presented a series of cases of gastric emphysema. They advocated the use of CT to guide management and to assist in the identification of associated extragastric pathologies [13].

Early endoscopy in the stable patient may be of use, particularly if the CT scan suggests gastric or esophageal involvement. Where diagnosis is emphysematous gastritis, gastroscopy and biopsy are advocated to facilitate a diagnosis, which can show evidence of submucosal abscesses or exudative gastritis $[14,15]$. In the above case, where the aetiology is obscure, the endoscopic findings of diffuse inflammation with diffusely friable, oedematous mucosa with mucopurulent exudates and rapid resolution of signs and symptoms may suggest a transient ischemia [5]. Because of transient ischemia, the mucosa may be injured or compromised thus allowing air to penetrate and dissect into the gastric wall. In these patients, nonoperative management and nasogastric decompression resulted in resolution of emphysema in 72 hours $[5,6]$.

Treatment focuses on early diagnosis, broad-spectrum antibiotic cover, nasogastric decompression of the stomach, and total parenteral nutrition, thus halting the vascular congestion and ensuing ischemia [3-5]. When considering gastric emphysema due to mechanical causes, clinical judgment should be carefully applied when determining which patients require surgical exploration and which can be observed safely. Selective non-operative management has been used successfully in the setting of secondary gastric emphysema, with nongangrenous gastric and esophageal 
emphysema [5]. Delayed perforation or bleeding is still possible, even following decompression. Surgical exploration is mandated in the presence of instability, perforation or for other indications, such as associated small bowel obstruction or ischemia of the small bowel $[1,4,7]$.

In our case, it is reasonable to presume that multiple factors have played a role in the development of acute gastric dilatation and gastric emphysema. This patient's comorbidities, gestational diabetes with poor diabetic control leading to gastroparesis, and chronic constipation are likely to have been a factor in the development of acute gastric dilatation and subsequently gastric emphysema. It is also likely that other factors can potentially aggravate the condition in this patient such as increase in intra-abdominal pressure because of gastric dilatation and acute massive haemorrhage, leading to transient poor perfusion of the gastrointestinal tract. Also the use of opiates for pain relief can further potentiate depression of gut motility. From the above case report and discussion, it is clear that the diagnosis and treatment of underlying cause of gastric emphysema are most important for a favourable outcome then simple gastric decompression.

\section{References}

[1] J. L. Powell, J. Payne, C. L. Meyer, and P. R. Moncla, "Gastric necrosis associated with acute gastric dilatation and small bowel obstruction," Gynecologic Oncology, vol. 90, no. 1, pp. 200-203, 2003.

[2] P. A. McKelvie and M. A. Fink, "A fatal case of emphysematous gastritis and esophagitis," Pathology, vol. 26, no. 4, pp. 490492, 1994.

[3] S. Luncă, A. Rikkers, and A. Stănescu, "Acute massive gastric dilatation: severe ischemia and gastric necrosis without perforation," Romanian Journal of Gastroenterology, vol. 14, no. 3, pp. 279-283, 2005.

[4] S. Lewis, A. Holbrook, and P. Hersch, "An unusual case of massive gastric distension with catastrophic sequelae," Acta Anaesthesiologica Scandinavica, vol. 49, no. 1, pp. 95-97, 2005.

[5] S. A. Mclaughlin and J. H. Nguyen, "Conservative management of nongangrenous esophageal and gastric pneumatosis," The American Surgeon, vol. 73, no. 9, pp. 862-864, 2007.

[6] T. Nagai, M. Yokoo, T. Tomizawa, and M. Mori, "Acute gastric dilatation accompanied by diabetes mellitus," Internal Medicine, vol. 40, no. 4, pp. 320-323, 2001.

[7] F-N. Cho, C.-B. Liu, J.-Y. Li, S.-N. Chen, and K. J. Yu, "Adynamic ileus and acute colonic pseudo-obstruction occurring after cesarean section in patients with massive peripartum hemorrhage," Journal of the Chinese Medical Association, vol. 72, no. 12, pp. 657-662, 2009.

[8] P. Y. Lin, M. S. Tsai, J. H. Chang, W. J. Chen, and C. H. Huang, "Gastric distension: a risk factor of pneumoperitoneum during cardiopulmonary resuscitation," The American Journal of Emergency Medicine, vol. 24, no. 7, pp. 878-879, 2006.

[9] E. Fraenkel, "Ueber einen Fall von Gastritis acuta emphysematosa wahrscheinlich mykotischen Ursprungs," Archiv für Pathologische Anatomie und Physiologie und für Klinische Medicin, vol. 118, no. 3, pp. 526-535, 1889.

[10] C. E. Yale and E. Balish, "The natural course of Clostridium perfringens-induced pneumatosis cystoides intestinalis," Journal of Medicine, vol. 23, no. 3-4, pp. 279-288, 1992.
[11] A. Ocepek, P. Skok, M. Virag, B. Kamenik, and M. Horvat, "Emphysematous gastritis-case report and review of the literature," Zeitschrift fur Gastroenterologie, vol. 42, no. 8, pp. 735-738, 2004.

[12] P. T. Johnson, K. M. Horton, B. H. Edil, E. K. Fishman, and W. W. Scott, "Gastric pneumatosis: the role of CT in diagnosis and patient management," Emergency Radiology, vol. 18, no. 1, pp. 65-73, 2011.

[13] F. Lassandro, M. L. M. Di Santo Stefano, A. Maria Porto, R. Grassi, M. Scaglione, and A. Rotondo, "Intestinal pneumatosis in adults: diagnostic and prognostic value," Emergency Radiology, vol. 17, no. 5, pp. 361-365, 2010.

[14] M. S. Soon, H. H. Yen, A. Soon, and O. S. Lin, "Endoscopic ultrasonographic appearance of gastric emphysema," World Journal of Gastroenterology, vol. 11, no. 11, pp. 1719-1721, 2005.

[15] N. R. Cordum, A. Dixon, and D. R. Campbell, "Gastroduodenal pneumatosis: endoscopic and histological findings," The American Journal of Gastroenterology, vol. 92, no. 4, pp. 692695, 1997. 


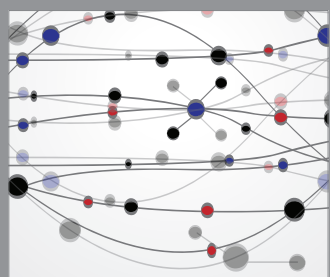

The Scientific World Journal
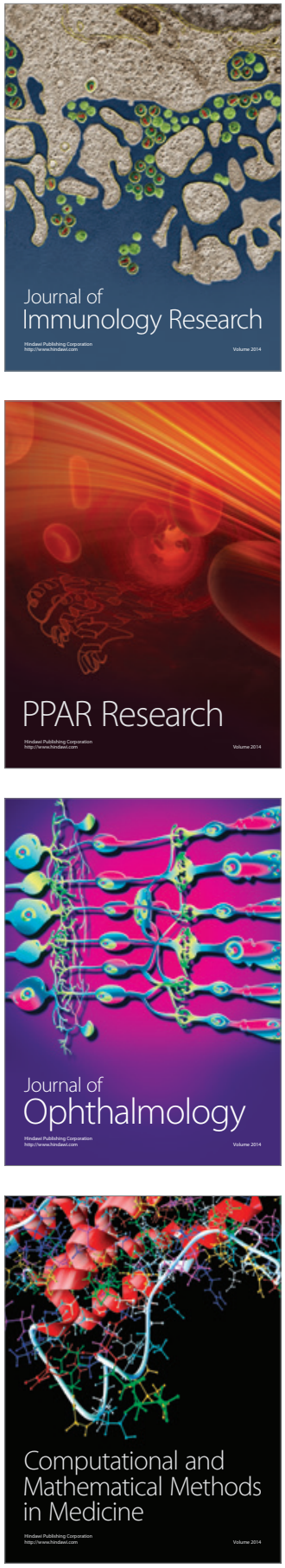

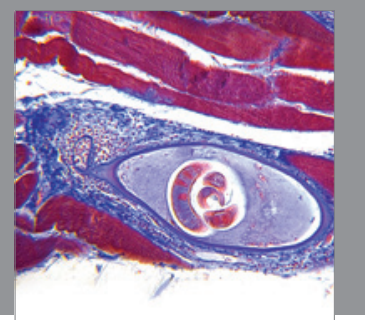

Gastroenterology

Research and Practice
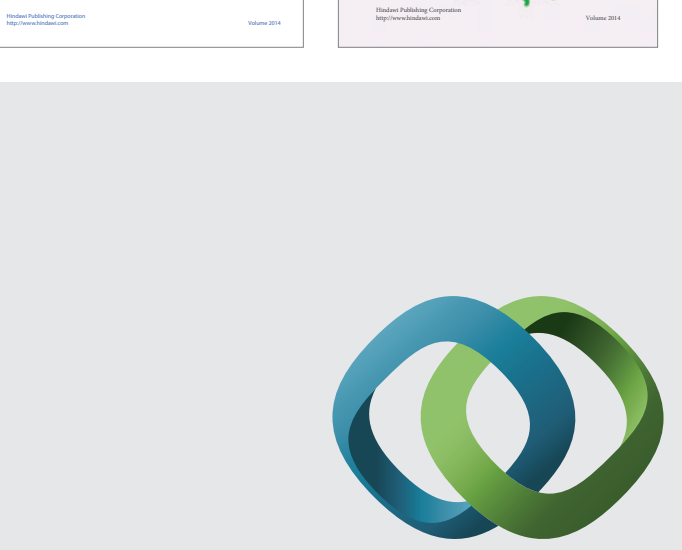

\section{Hindawi}

Submit your manuscripts at

http://www.hindawi.com
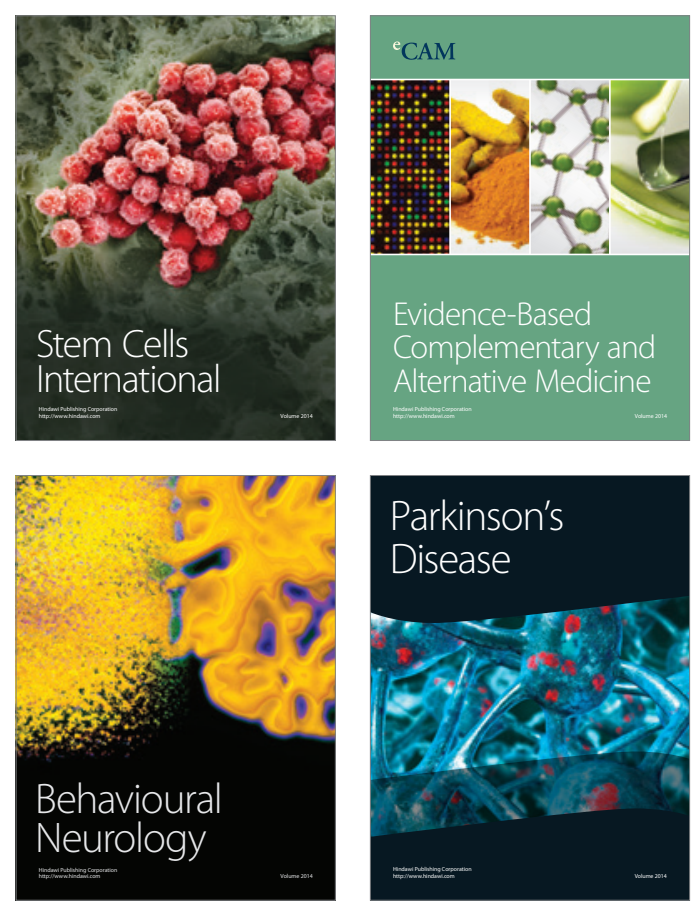

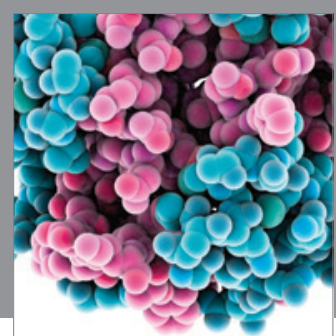

Journal of
Diabetes Research

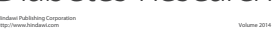

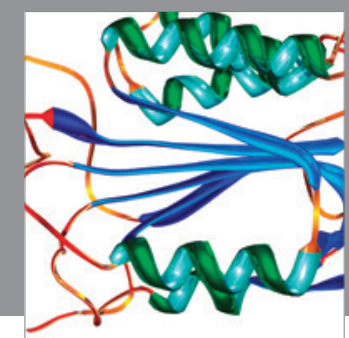

Disease Markers
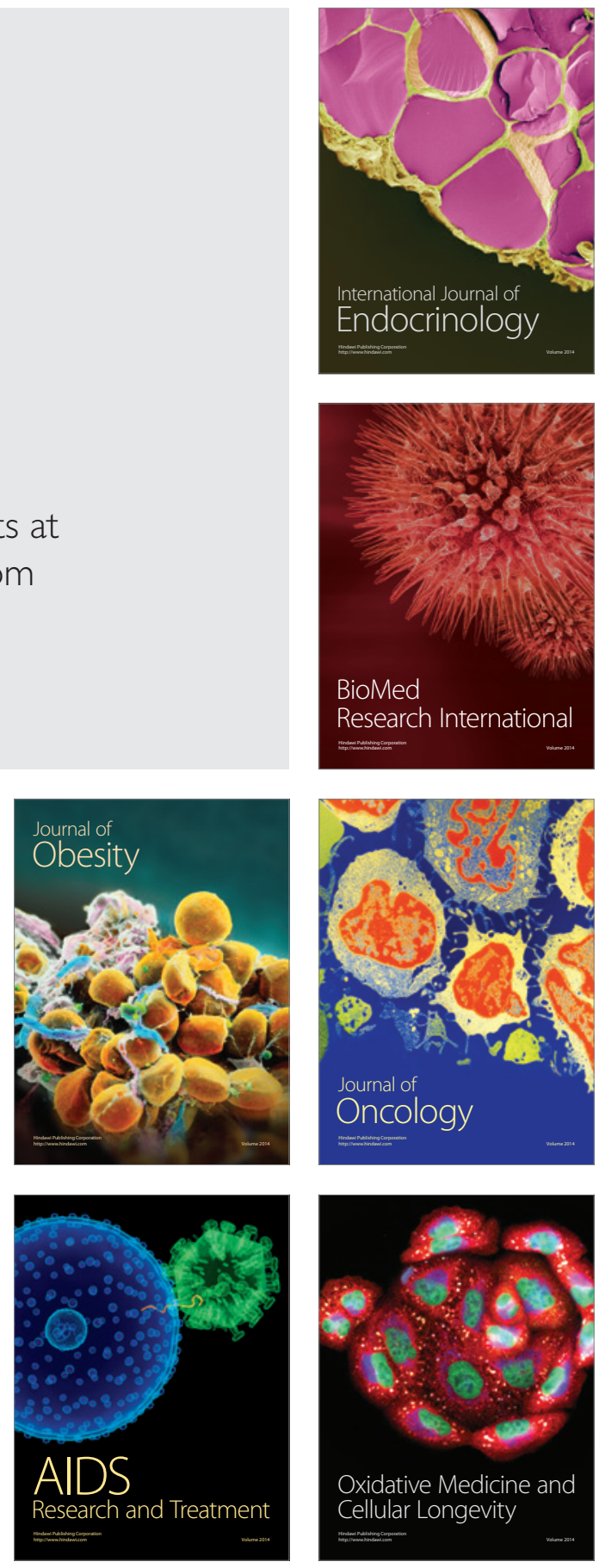